\title{
Stability of selenium and iodine in the functional meat products prepared with seaweeds under different cooking procedures
}

\section{Yuliya Kryzhova, Marya Antonuk, Viktor Stabnikov, Olena Stabnikova}

\author{
National University of Food Technologies, Kyiv, Ukraine
}

\section{Keywords: \\ Functional \\ Food \\ Seaweeds \\ Selenium \\ Iodine}

\section{Article history: \\ Received 21.05.2020 \\ Received in revised \\ form 03.09.2020 \\ Accepted 25.03.2021}

\section{Corresponding author:}

Viktor Stabnikov

E-mail:

vstabnikov1@

gmail.com

DOI: $10.24263 / 2304-$

974X-2021-10-1-12

\section{Abstract}

Introduction. The aim of this study was determination of the stability of selenium and iodine in the functional meat products prepared with seaweeds under different cooking procedures.

Materials and methods. Three edible seaweeds Fucus, Cystoseira, and Laminaria were used in the study. Different meat products with addition of seaweeds were prepared. Selenium concentration was measured using diaminonaphtalene method. Content of iodine was determined by inverse voltammetry.

Results and discussion. Meat-based food products prepared with seaweeds to enrich them with iodine and selenium were proposed. Seaweed Laminaria had too high iodine and selenium contents to be used for preparation of dietary products. Cystoseira was the better source of iodine than Fucus. All ready-to-eat products with Cystoseira had higher iodine content than ones with Fucus. Iodine losses were lower and the contents of iodine in ready-to-eat products were higher in the products prepared at lower temperature $100-110{ }^{\circ} \mathrm{C}$ (steamed cutlets) in comparison with $170{ }^{\circ} \mathrm{C}$ (fried cutlets). Altogether, method used for product preparation had a great influence on iodine losses during cooking. The biggest losses were observed for products prepared in liquid: $50 \%$ iodine losses in meat balls braised in sauce and $61 \%$ in quenelles cooked in soup. Loss of iodine in dumpling was lower, $38 \%$, maybe due to protection of meat with the dough cover. The lowest loss of iodine, around $17 \%$, was in grilled sausages due to relatively low temperature of cooking and absence of liquid environment.

Cystoseira was a lit bit better source of selenium than Fucus. All ready-to-eat products with Cystoseira had slightly higher selenium content than ones with Fucus. Influence of temperature and method for food preparation was not so evident, selenium losses varied from 19 to $27 \%$ for steam cutlets, meat balls and even for quenelles and dumpling prepared with Laminaria. The lowest loss of selenium, around 7\%, was in the grilled sausages.

Conclusion. Fried and steamed minced-meat cutlets, meat balls, and grilled sausages prepared with addition of $2 \%(\mathrm{w} / \mathrm{w})$ of seaweeds Cystoseira or Fucus can be recommended to be used as the functional food supplying needed daily quantity of iodine and selenium. 


\section{Introduction}

Meat products are essential part of a daily ration supplying human with valuable nutrients. To improve meat products quality these products can be designed as the functional food by direct incorporation of different ingredients during meat processing (Bhat and Bhat, 2011; Zhang et al., 2010). Among ingredients used for the preparation of functional food, edible seaweeds are considered as a good source of antioxidants, dietary fibers, essential amino acids, vitamins, unsaturated fatty acids, carotenoids and abundant minerals that can be incorporated in meat, fish, bakery and others products (Bocanegra et al., 2009; Circuncisao et al., 2018).

It was shown that the addition of seaweeds or seaweeds extracts can improve the health value, shelf-life and quality of food (Roohinejad et al., 2017). There are some attempts to use seaweeds in the preparation of meat-based functional food products. Seaweeds, for example "wakame" (Undaria pinnatifida), "nori" (Porphyra umbilicalis), and "sea spaghetti" (Himanthalia elongata) were used as the sources of bioactive substances to improve fatty acid content of some modified meat products such as frankfurters, patties and restructured steaks (Cofrades et al., 2017). There were also attempts to prepare bread using seaweeds Lemna minor or Ulva rigida to extend its shelf-life (Kilınc et al., 2013).

Edible seaweed (macroalgae) is a rich source of essential minerals and trace elements needed for human nutrition, particular selenium (Se) and iodine (I) (Circuncisao et al., 2018; Cherry et al., 2019), adequate intakes of which are required for optimal thyroid function (Schomburg and Kohrle, 2008).

The aim of this study was determination of the stability of selenium and iodine in the functional meat products prepared with seaweeds under different cooking procedures (Figure $1)$.

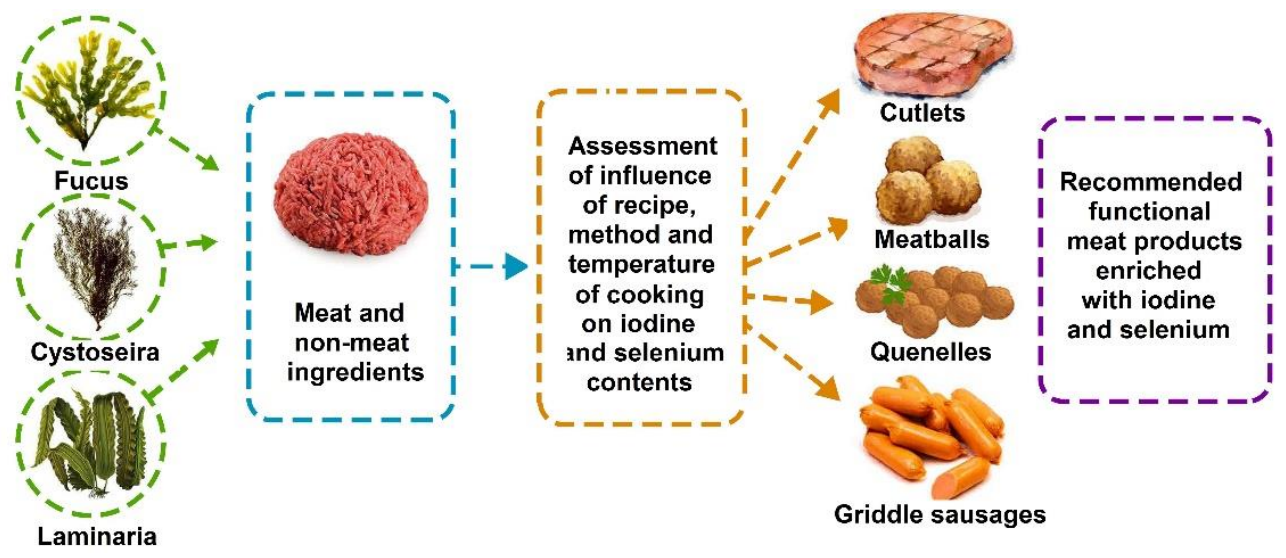

Figure 1. Research scheme 


\section{Materials and methods}

\section{Seaweeds}

Three edible seaweeds from the brown algae family were chosen for this study: (1) Fucus, "sea oak", which has high contents of iodine, calcium, magnesium, iron and other minerals (Pereira, 2011); (2) Black sea brown alga Cystoseira, which is a source of iodine and selenium and is used as a food additive (Pereira, 2016), and Laminaria, which traditionally has been used as a food additive being a source of biological active substances including iodine in natural form and it is considered that it may be useful for preventing lifestyle-related diseases (Kılınc, 2013; Shirosaki and Koyama, 2011). Seaweeds have been dried in the conventional oven at $100{ }^{\circ} \mathrm{C}$ for $2-3$ hours for the moisture content $12-13 \%$, and then milled to a fine powder. The fine powder of seaweeds before addition to the minced meat was mixed with water with temperature $20^{\circ} \mathrm{C}$ in the following ratio: mass of Cystoseira to water 1:3, mass of Fucus or Laminaria to water 1:4, and exposed for hydration or 6-12 hours. Moisture content of seaweeds was determined after drying at $105^{\circ} \mathrm{C}$ to a constant weight.

\section{Trace elements determination}

Selenium concentration was measured by minifluorometer (mode TD-360, Turner Design, Sunnyvale, CA, USA) using diaminonaphtalene method (Watkinson, 1966). The samples of biomass were preliminary digested using $\mathrm{HNO}_{3}, \mathrm{HClO}_{4}$ and $\mathrm{HCl}$. The determination of selenium was made in quartz cuvette $3 \mathrm{ml}$. The excitation wavelength was $369 \mathrm{~nm}$, the fluorescence emission wavelength was $525 \mathrm{~nm}$.

Content of iodine was determined by inverse voltammetry using voltametric analyser ABA2 (Scientific Industrial Enterprise, Saint Petersburg, Russia) (Korzun and Palamarek, 2014).

\section{Thermal treatment of meat products}

Meat products were treated at different temperatures: meat-ball were cooked by braising in sauce at $100{ }^{\circ} \mathrm{C}$, quenelle (meat ball cooked in broth) were cooked at $100{ }^{\circ} \mathrm{C}$, boiling of dumplings was done at $100^{\circ} \mathrm{C}$, preparation of steamed minced cutlets was done at $100-110^{\circ} \mathrm{C}$, frying of minced cutlets was done at $150-170^{\circ} \mathrm{C}$, and cooking of sausages on the grill was done at $110^{\circ} \mathrm{C}$.

\section{Technological operations}

Fried and steamed minced-meat cutlets. Ingredients for cutlets included chicken meat, beef, semi-fat pork, minced fish, soya mince, and also barley, potato, eggs, onion, carrot, sweet butter, bread, salt and spices. Barley was hydrated with water in ratio 1:2 for 30 minutes. Hydrated seaweeds Fucus or Cystoseira were added in quantity 2\% (by dry weight) to raw stuff and mixed for 7 minutes to obtain indiscrete mass. Eight different recipes were used for cutlets preparation: chicken meat, minced fish, barley with biomass of Cystoseira (1) or Fucus (2); chicken meat, semi-fat pork, barley with biomass of Cystoseira (3) or Fucus (4), minced fish, soya mince, with biomass of Cystoseira (5) or Fucus (6); beef, semi-fat pork, raw potato and biomass of Cystoseira (7) or Fucus (8). Content of iodine was determined in raw, fried and steamed minced-meat cutlets. Fried minced cutlets were stored at temperature $-10{ }^{\circ} \mathrm{C}$ for 14 days (freezing) and then content of iodine was checked again. 
Meat-ball. Ingredients for meat balls included chicken meat, semi-fat pork, minced fish, taking in different proportions, and also barley, eggs, sweet butter, bread, salt and black pepper. Hydrated seaweeds Cystoseira or Fucus were added in quantity $2 \%$ (by dry weight) to raw stuff and mixed for 7 minutes to obtain indiscrete mass. Meat balls (with weight of 70 $\mathrm{g}$ each) were prepared by braising in sauce at temperature $100^{\circ} \mathrm{C}$. Four different recipes were used for meat ball preparation: semi-fat pork, chicken meat, rice grits, barley flour, seaweed Cystoseira (1) or Fucus (2); minced fish, wheat bread, milk, barley flour, seaweed Cystoseira (3) or Fucus (4).

Quenelles. Quenelles (small meat balls with weight $15 \mathrm{~g}$ each) were cooked in a broth at $100^{\circ} \mathrm{C}$. Hydrated seaweed Laminaria was added in quantity $2 \%$ (by dry weight) to raw stuff and mixed for 7 minutes to obtain indiscrete mass. Two different recipes were used for quenelles preparation: semi-fat pork, chicken meat, barley flour, egg, carrot, onion, salt, black pepper and seaweed Laminaria (1); minced fish hake, white bread, sweet butter, barley flour, egg, carrot, onion, salt, black pepper and seaweed Laminaria (2).

Dumplings. Ingredients for dumplings included minced pork, minced beef, fat pork (recipe 1) and fish pike perch (recipe 2), and also onion, chicken eggs, and spices. Hydrated seaweed Laminaria was added in quantity $2 \%$ (by dry weight).

Grilled sausages. Sausages on the grill were prepared at $110{ }^{\circ} \mathrm{C}$ for $60 \mathrm{~min}$. Ingredients for sausage included chicken meat, semi-fat pork, lard, bean, onion, and species. Hydrated seaweeds Fucus (recipes 1 and 3) or Cystoseira (recipes 2 and 4) were added in quantity 2\% (by dry weight).

\section{Results and discussion}

Fried minced-meat cutlets. Iodine losses in minced-meat cutlets after frying at 150 $170{ }^{\circ} \mathrm{C}$ varied from 20 to $37 \%$ in products with Cystoseira (recipes 1, 3, 5, and 7) and from 20 to $23 \%$ in products with Fucus (recipes (2, 4, 6, and 8) ( Figure 2).

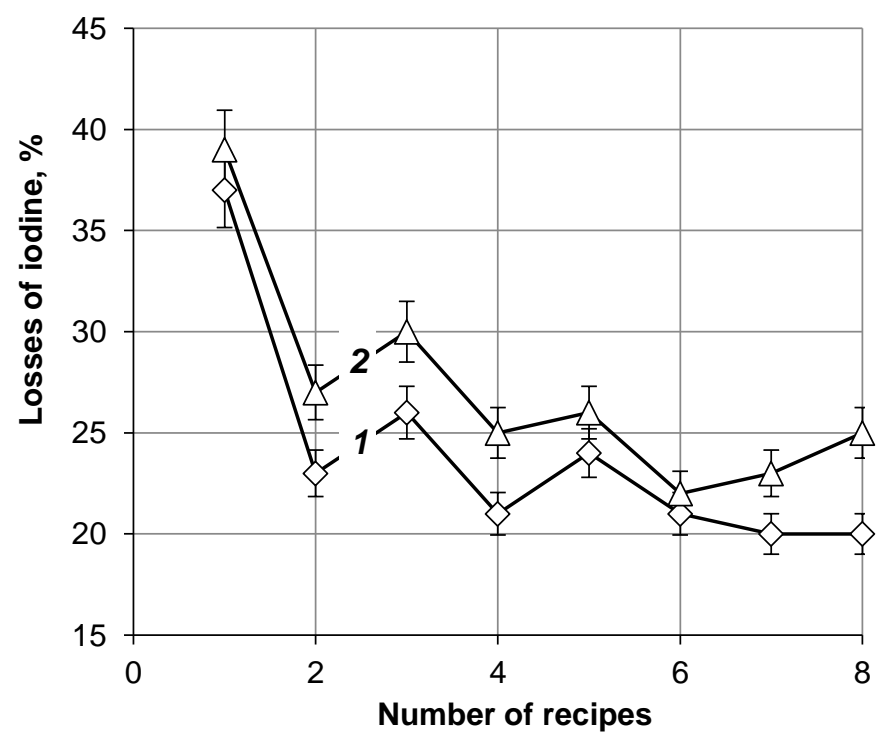

Figure 2. Iodine losses in fried minced-meat cutlets prepared by different recipes 1 - fried; 2 - fried after freezing 
Content of iodine in fried minced-meat cutlets with mass $50 \mathrm{~g}$ varied from 276 to 315 mcg: $189 \mathrm{mcg}$ (recipe 1); $215 \mathrm{mcg}$ (recipe 2); $276 \mathrm{mcg}$ (recipe 3); $188 \mathrm{mcg}$ (recipe 4); 315 mcg (recipe 5); $216 \mathrm{mcg}$ (recipe 6); $188 \mathrm{mcg}$ (recipe 7); $186 \mathrm{mcg}$ (recipe 8). It was shown that the losses of iodine depend on recipe notwithstanding what kind of seaweeds was used. During preparation of fried cutlets, the higher losses were observed for recipes 3 and 4, which differed only by seaweed added ( 3 with Cystoseira) and ( 4 with Fucus), and the content of iodine in $50 \mathrm{~g}$ of fried minced-meat cutlets were 276 and $188 \mathrm{mcg}$, respectively. Meanwhile, the lowest losses of iodine were observed for recipes 5 and 6, which also differed only by seaweed added (5 with Cystoseira) and (6 with Fucus), and the content of iodine in $50 \mathrm{~g}$ of fried minced-meat cutlets were 315 and $216 \mathrm{mcg}$, respectively.

Fried minced-meat cutlets were stored at $-10^{\circ} \mathrm{C}$ for 14 days. Losses of iodine during storage under freezing were negligeable, around 2\%, and consisted from 23 to $39 \%$ in products with Cystoseira (recipes 1, 3, 5, and 7) and from 22 to $30 \%$ in products with Fucus (Figure 2).

Steamed minced-meat cutlets. Losses of iodine in steamed minced-meat cutlets prepared at temperature $100-110^{\circ} \mathrm{C}$ were lower than in fried ones and were around $22 \%$ in products with Cystoseira (recipes 1 and 3) and were around $15 \%$ in products with Fucus (recipes 2 and 4) (Figure 3).

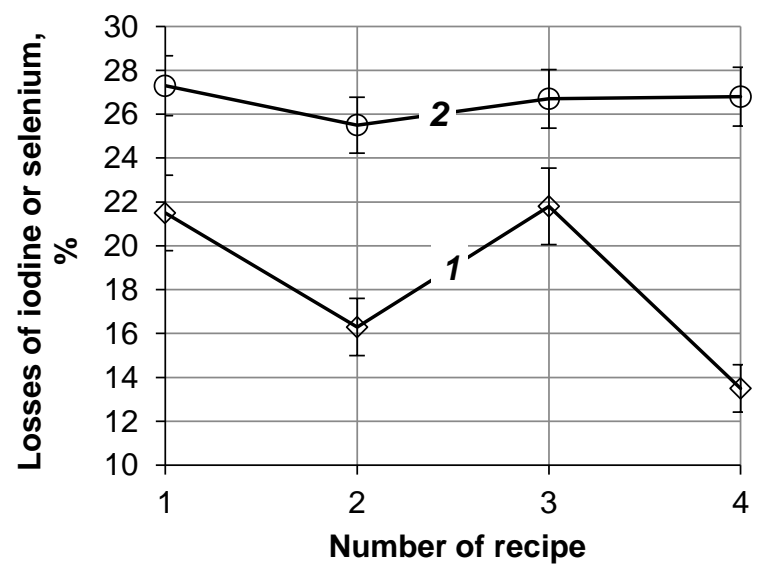

Figure 3. Iodine and selenium losses in steamed minced-meat cutlets prepared by different recipes:

1 - iodine; 2 - selemim

Content of iodine in steamed minced-meat cutlets with mass $50 \mathrm{~g}$ varied from 202 to 342 mcg: $342 \mathrm{~m} \mathrm{cg}$ (recipe 1); $214 \mathrm{mcg}$ (recipe 2); $321 \mathrm{mcg}$ (recipe 3); $202 \mathrm{mcg}$ (recipe 4). Content of iodine in fried minced-meat cutlets prepared without seaweeds (control) with mass $50 \mathrm{~g}$ varied from $0.32 \mathrm{mcg}$ to $1.06 \mathrm{mcg}$.

Losses of selenium in steamed minced-meat cutlets were almost the same for all recipes: around 27\% in products with Cystoseira (recipes 1 and 3) and around 26\% in products with Fucus (recipes 2 and 4) (Figure 2). Content of selenium in steamed minced-meat cutlets with mass $50 \mathrm{~g}$ were: $40 \mathrm{mcg}$ (recipe 1); $35 \mathrm{mcg}$ (recipe 2); $33 \mathrm{mcg}$ (recipe 3); $30 \mathrm{mcg}$ (recipe 4). Content of selenium in steamed minced-meat cutlets prepared without seaweeds (control) with mass $50 \mathrm{~g}$ varied from $20 \mathrm{mcg}$ to $28 \mathrm{mcg}$. 


\section{- Food Technology}

Meat-balls. Meat-balls and fish-balls were cooked by braising in sauce at $100{ }^{\circ} \mathrm{C}$. Iodine loss in both types of balls with Cystoseira (recipes 1 and 3) Fucus (recipes 2 and 4) was similar 50.1 $\pm 1.6 \%$. Contents of iodine in $50 \mathrm{~g}$ of balls with Cystoseira were $186.2 \mathrm{mcg}$ (recipe 1) and $181.1 \mathrm{mcg}$ (recipe 3); with Fucus; $134.9 \mathrm{mcg}$ (recipe 2); $146.3 \mathrm{mcg}$ (recipe 4). Content of iodine in meat balls prepared without seaweeds (control) with mass $50 \mathrm{~g}$ varied from $0.01 \mathrm{mcg}$ to $0.04 \mathrm{mcg}$.

Selenium loss in both types of balls with Cystoseira (recipes 1 and 3) or Fucus (recipes 2 and 4) was similar 20.1 $\pm 1.2 \%$. Content of selenium in meat balls with mass $50 \mathrm{~g}$ were: 38.9 mcg (recipe 1); $34.1 \mathrm{mcg}$ (recipe 2); $19.2 \mathrm{mcg}$ (recipe 3); $21.6 \mathrm{mcg}$ (recipe 4). Content of selenium in meat balls with mass $50 \mathrm{~g}$ prepared without seaweeds (control 1) was $3.6 \mathrm{mcg}$ (control 1 for recipes 1 and 3 ) and to $6.2 \mathrm{mcg}$ (control 2 for recipes 2 and 4).

Quenelles. Meat quenelles (recipe 1) and fish quenelles (recipe 2) with Laminaria with weight $15 \mathrm{~g}$ each cooked in the soup at $100^{\circ} \mathrm{C}$. Iodine loss was $60.9 \%$ for meat quenelles and $56.1 \%$ for fish quenelles. Content of iodine in $50 \mathrm{~g}$ of quenelles was $574 \mathrm{mcg}$ (recipe 1) and $693 \mathrm{mcg}$ (recipe 2). Selenium loss was $15.9 \%$ for meat quenelles and $20.3 \%$ for fish quenelles. Content of selenium in $50 \mathrm{~g}$ of quenelles was $136 \mathrm{mcg}$ (recipe 1) and $125 \mathrm{mcg}$ (recipe 2).

Dumplings. Meat dumplings (recipe 1) and fish dumplings (recipe 2) with Laminaria were boiled at $100{ }^{\circ} \mathrm{C}$. Iodine loss was $38.2 \%$ for meat quenelles and $40.6 \%$ for fish quenelles. Content of iodine in $50 \mathrm{~g}$ of dumplings was $373 \mathrm{mcg}$ (recipe 1) and $339.0 \mathrm{mcg}$ (recipe 2). Selenium loss was $20.1 \%$ for meat dumpling and $21.2 \%$ for fish quenelles. Contents of selenium in $50 \mathrm{~g}$ of dumplings were $82 \mathrm{mcg}$ (recipe 1) and $80 \mathrm{mcg}$ (recipe 2).

Griddle sausages. Sausages on the grill were prepared at $110^{\circ} \mathrm{C}$ for $60 \mathrm{~min}$. Hydrated seaweeds Cystoseira (recipes 1 and 3) or Fucus (recipes 2 and 4) were added in quantity 2\% (by dry weight). Losses of iodine and selenium were 15.4 and 7.2\% (recipe 1), 16.0 and 6.1 $\%$ (recipe 2), 15.0 and $8.2 \%$ (recipe 3), 20.5 and $7.7 \%$ (recipe 4), respectively. Content of iodine and selenium, mcg/50g, were 270 and 45.4 (recipe 1), 243 and 39.1 (recipe 2), 306 and 40.2 (recipe 3), 218 and 36.0 (recipe 4), respectively.

\section{Compatible analysis of seaweeds application as a source of selenium and iodine to enhance meat products}

Average data of all meat products without taking into account influence of recipes are shown in Table 1.

Cystoseira was the better source of iodine than Fucus. All ready-to-eat products with Cystoseira had higher iodine content than ones with Fucus. Influence of temperature is evident, especially due to comparison of iodine content in fried and steamed minced-meat cutlets: iodine losses were lower and the contents of iodine in ready-to-eat products were higher when in the products prepared at lower temperature $100-110{ }^{\circ} \mathrm{C}$ (steamed cutlets) in comparison with $170{ }^{\circ} \mathrm{C}$ (fried cutlets). Altogether, method used for product preparation had a great influence on iodine losses during cooking. The biggest losses were observed for products prepared in liquid: $50 \%$ iodine losses in meat balls braised in sauce and $61 \%$ in quenelles cooked in soup. Loss of iodine in dumpling was lower, 38\%, maybe due to protection of meat with the dough cover. The lowest loss of iodine, around 17\%, was in grilled sausages due to relatively low temperature of cooking and absence of liquid environment. 
Table 1

Losses of iodine and selenium in meat products enriched with seaweeds prepared by different cooking methods

\begin{tabular}{|c|c|c|c|c|c|c|}
\hline \multirow{2}{*}{$\begin{array}{c}\text { Meat } \\
\text { products }\end{array}$} & \multirow{2}{*}{$\begin{array}{c}\text { Temperature, } \\
{ }^{\circ} \mathrm{C}\end{array}$} & \multirow{2}{*}{ Seaweed } & \multicolumn{2}{|c|}{ Iodine } & \multicolumn{2}{|c|}{ Selenium } \\
\hline & & & $\begin{array}{c}\text { loss, } \\
\%\end{array}$ & $\mathrm{mcg} / 50 \mathrm{~g}$ & $\begin{array}{c}\text { loss, } \\
\%\end{array}$ & $\mathrm{mcg} / \mathbf{5 0 g}$ \\
\hline \multirow{2}{*}{$\begin{array}{l}\text { Fried } \\
\text { cutlets }\end{array}$} & \multirow[t]{2}{*}{$150-170$} & Cystoseira & 27 & 242 & $\mathrm{~N} / \mathrm{d}$ & $\mathrm{N} / \mathrm{d}$ \\
\hline & & Fucus & 22 & 201 & $\mathrm{~N} / \mathrm{d}$ & $\mathrm{N} / \mathrm{d}$ \\
\hline \multirow{2}{*}{$\begin{array}{l}\text { Steamed } \\
\text { cutlets }\end{array}$} & \multirow[t]{2}{*}{$100-110$} & Cystoseira & 22 & 332 & 27 & 37 \\
\hline & & Fucus & 15 & 208 & 26 & 32 \\
\hline \multirow{2}{*}{$\begin{array}{c}\text { Meat } \\
\text { ball }\end{array}$} & \multirow[t]{2}{*}{100} & Cystoseira & 50 & 186 & 21 & 39 \\
\hline & & Fucus & 50 & 135 & 19 & 34 \\
\hline Quenelles & 100 & Laminaria & 61 & 574 & 16 & 136 \\
\hline Dumpling & 100 & Laminaria & 38 & 373 & 51 & 82 \\
\hline \multirow{2}{*}{$\begin{array}{c}\text { Grilled } \\
\text { sausages }\end{array}$} & \multirow[t]{2}{*}{110} & Cystoseira & 16 & 305 & 8 & 43 \\
\hline & & Fucus & 18 & 200 & 7 & 38 \\
\hline
\end{tabular}

Recommended Dietary Allowances (RDAs) for iodine is $150 \mathrm{mcg}$ per day for most adults (Trumbo et al., 2001) and $250 \mathrm{mcg}$ per day for pregnant women (WHO, 2007). It looks that Laminaria has too high iodine content, so, it is not reasonable to use it for preparation of functional meat product to prevent over dosage of iodine daily intake. However, Cystoseira and Fucus can be recommended to be used in quantity $2 \%$ for preparation of functional meat product to enrich diet with iodine.

Fried and steamed minced-meat cutlets, meat balls, and grilled sausages prepared with addition of seaweeds Cystoseira or Fucus can be recommended to be used as functional food supplying needed daily quantity of iodine.

Cystoseira was a lit bit better source of selenium than Fucus. All ready-to-eat products with Cystoseira had slightly higher selenium content than ones with Fucus. Influence of temperature and method for food preparation was not so evident, selenium losses varied from 19 to $27 \%$ for steam cutlets, meat balls and even for quenelles and dumpling prepared with Laminaria. The lowest loss of selenium, around 7\%, was in the grilled sausages.

According to World Health Organization, the recommended daily intake of selenium is from 30 to $40 \mu \mathrm{g} /$ day (Kieliszek and Blazejak, 2016). Daily consumption of selenium by population in different countries varies from 28 to $150 \mu \mathrm{g}$ Se per day. Daily recommended allowances of selenium in Ukraine are $70 \mu \mathrm{g}$ for men and $55 \mu \mathrm{g}$ for women (Stabnikova et al., 2019). However, a large part of the Ukrainian population has a shortage of selenium in their rations. For example, daily consumption of selenium by people living in town Slavutich, near Chernobyl nuclear power plant accident site, consists only $26 \%$ of recommended daily allowance (Spirichev et al., 2006). It looks that Laminaria has too high content of selenium to be used for preparation of dietary products as a source of selenium. However, minced meat cutlets, meat balls and grilled sausages prepared with seaweeds Cystoseira and Fucus can serve as the sources not only iodine but selenium also.

The quality of meat products with seaweeds were estimated by organoleptic properties such as product appearance, view of the cross-section, consistency, color, taste and smell. The volunteers from the National University of Life and Environmental Sciences and the National University of Food Technologies made conclusion that there was no significant difference between meat products prepared with seaweeds and control ones. 


\section{Conclusions}

Fried and steamed minced-meat cutlets, meat balls, and grilled sausages prepared with addition of seaweeds Cystoseira or Fucus can be recommended to be used as functional food supplying needed daily quantity of iodine and selenium.

Losses of iodine in meat products prepared with seaweeds depended on recipe, notwithstanding what kind of seaweeds was used. Meanwhile, losses of iodine during storage at $-10^{\circ} \mathrm{C}$ for 14 days were negligeable, around $2 \%$. The method that was used for product cooking as well as temperature of cooking had also a great influence on iodine and selenium losses during food preparation. Lowest losses of both elements were observed for grilled sausage.

Seaweed Laminaria has too high iodine and selenium contents to be used for preparation of functional meat products. However, minced meat cutlets, meat balls and grilled sausages prepared with seaweeds Cystoseira or Fucus can serve as the sources for iodine and selenium in preparation of functional meat products for consumption by Ukrainian population.

\section{References}

Bhat Z.F., Bhat H. (2011) Functional meat product. A review, International Journal of Meat Science, 1, pp. 1-14.

Bocanegra A., Bastida S., Benedí J., Rodenas S., Sanchez-Muniz F.J. (2009), Characteristics and nutritional and cardiovascular-health properties of seaweeds, Journal of Medicinal Food, 12(2), pp. 236-258.

Cherry P., O'Hara C., Magee P.J., McSorley E.M., Allsopp P.J. (2019), Risks and benefits of consuming edible seaweeds, Nutrition Reviews, 77(5), pp. 307-329.

Circuncisao A.R., Catarino M.D., Cardoso S.M., Silva A.M.S. (2018), Minerals from macroalgae origin: Health benefits and risks for consumers, Marine Drugs, 16(11), p. 400.

Cofrades S., Benedí J., Garcimartin A., Sanchez-Muniz F.J., Jimenez-Colmenero F. (2017), A comprehensive approach to formulation of seaweed-enriched meat products: From technological development to assessment of healthy properties, Food Research International, 99(3), pp. 1084-1094.

Kieliszek M., Blazejak S. (2016), Current knowledge on the importance of selenium in food for living organisms: a review, Molecules, 21, p. 609.

Kilinc B., Cirik S., Turan G., Tekogul H., Koru E. (2013), Seaweeds for food and industrial applications, in I. Muzzalupo (Ed.), Food Industry, Intech, pp. 735-748.

Korzun V.N., Palamarek K.V. (2014), Concentration of iodine in vegetable cheese pasta, Food Science and Technology, 2, pp. 10-14.

Pereira L. (2011), A review of the nutrient composition of selected edible seaweeds, in V. H. Pomin (Ed.), Seaweed: Ecology, Nutrient Composition and Medicinal Uses, Nova Science Publishers, Inc., pp. 281-304.

Pereira L. (2016), Edible Seaweeds in the World. CRC Press.

Roohinejad S., Koubaa M., Barba F.J., Saljoughian S., Amid M., Greiner R. (2017), Application of seaweeds to develop new food products with enhanced shelf-life, quality and health-related beneficial properties, Food Research International, 99 (Pt 3), pp. 1066-1083.

Schomburg L., Kohrle J. (2008), On the importance of selenium and iodine metabolism for thyroid hormone biosynthesis and human health, Molecular Nutrition \& Food Research, 52(11), pp. 1235-1246. 
Shirosaki M., Koyama T. (2011), Laminaria japonica as a food for the prevention of obesity and diabetes, Advances in Food and Nutrition Research, 64, pp. 199-212.

Spirichev V.B., Donchenko G.V., Blazheyevich N.V. et al. (2006), Study of vitamin status and provision with micro- and macroelements of limited groups of people at different time periods since the accident at Chernobyl nuclear power plant, Ukrainian Biochemical Journal, 78, pp. 5-26.

Stabnikova O., Antonuk M., Stabnikov V., Arsen'eva L. (2019), Ukrainian dietary bread with selenium-enriched malt, Plant Foods for Human Nutrition, 74(2), pp. 157-163.

Trumbo P., Yates A.A., Schlicker S., Poos M. (2001), Dietary reference intakes: vitamin A, vitamin $\mathrm{K}$, arsenic, boron, chromium, copper, iodine, iron, manganese, molybdenum, nickel, silicon, vanadium, and zinc, Journal of the Academy of Nutrition and Dietetics, 101(3), pp. 294-301.

Watkinson J.H. (1966), Fluorometric determinations of selenium in biological material with 2,3, diaminonaphtalene, Analytical Chemistry, 38(1), pp. 92-103.

WHO. (2007), World Health Organization. United Nations Children's Fund and International Council for the Control of Iodine Deficiency Disorders. Assessment of iodine deficiency disorders and monitoring their elimination. 3rd ed. Geneva, Switzerland.

Zhang W., Xiao S., Samaraweera H., Lee E J., Ahn D.U. (2010), Improving functional value of meat products, Meat Science, 86(1), pp. 15-31. 